\title{
Polyamine metabolism is involved in adipogenesis of 3T3-L1 cells
}

\author{
Ikumi Ishii · Yoshihiko Ikeguchi · Hiroshi Mano • \\ Masahiro Wada • Anthony E. Pegg • \\ Akira Shirahata
}

Received: 29 January 2011 / Accepted: 26 March 2011/Published online: 2 August 2011

(C) The Author(s) 2011. This article is published with open access at Springerlink.com

\begin{abstract}
Polyamines spermidine and spermine are known to be required for mammalian cell proliferation and for embryonic development. Alpha-difluoromethylornithine (DFMO), an inhibitor of ornithine decarboxylase (ODC) a limiting enzyme of polyamine biosynthesis, depleted the cellular polyamines and prevented triglyceride accumulation and differentiation in 3T3-L1 cells. In this study, to explore the function of polyamines in adipogenesis, we examined the effect of polyamine biosynthesis inhibitors on adipocyte differentiation and lipid accumulation of 3T3-L1 cells. The spermidine synthase inhibitor trans-4methylcyclohexylamine (MCHA) increased spermine/ spermidine ratios, whereas the spermine synthase inhibitor $N$-(3-aminopropyl)-cyclohexylamine (APCHA) decreased the ratios in the cells. MCHA was found to decrease lipid accumulation and GPDH activity during differentiation, while APCHA increased lipid accumulation and GPDH activity indicating the enhancement of differentiation.
\end{abstract}

I. Ishii · Y. Ikeguchi $(\bowtie) \cdot$ A. Shirahata

Laboratory of Biochemistry,

Department of Pharmaceutical Sciences,

Faculty of Pharmaceutical Sciences, Josai University,

1-1 Keyakidai, Sakado, Saitama 350-0295, Japan

e-mail: ikeguchi@josai.ac.jp

H. Mano - M. Wada

Laboratory of Food Sciences, Department of Human

Nutrition and Clinical Dietetics, Faculty of Pharmaceutical

Sciences, Josai University, 1-1 Keyakidai, Sakado,

Saitama 350-0295, Japan

\section{A. E. Pegg}

Department of Cellular and Molecular Physiology,

The Pennsylvania State University College of Medicine,

Hershey, PA 17033, USA
The polyamine-acetylating enzyme, spermidine/spermine $N^{1}$-acetyltransferase (SSAT) activity was increased within a few hours after stimulus for differentiation, and was found to be elevated by APCHA. In mature adipocytes APCHA decreased lipid accumulation while MCHA had the opposite effect. An acetylpolyamine oxidase and spermine oxidase inhibitor MDL72527 or an antioxidant $\mathrm{N}$-acetylcysteine prevented the promoting effect of APCHA on adipogenesis. These results suggest that not only spermine/spermidine ratios but also polyamine catabolic enzyme activity may contribute to adipogenesis.

Keywords Adipogenesis - Polyamine metabolism . Spermine $\cdot$ Spermidine $\cdot$ Polyamine oxidation $\cdot 3 T 3-L 1$

$\begin{array}{ll}\text { Abbreviations } & \\ \text { AcPAO } & \text { Acetylpolyamine oxidase } \\ \text { APCHA } & N \text {-(3-aminopropyl)-cyclohexylamine } \\ \text { CS } & \text { Calf serum } \\ \text { DEX } & \text { Dexamethasone } \\ \text { DFMO } & \alpha \text {-Difluoromethylornithine } \\ \text { DMEM } & \text { Dulbecco's modified eagle's medium } \\ \text { FBS } & \text { Fetal bovine serum } \\ \text { GPDH } & \text { Glycerol-3-phosphate dehydrogenase } \\ \text { Gy } & \text { Gyro } \\ \text { IBMX } & \text { Isobutylmethylxanthine } \\ \text { INS } & \text { Insulin } \\ \text { MAO } & \text { Monoamine oxidase } \\ \text { MCHA } & \text { trans-4-Methylcyclohexylamine } \\ \text { MDL72527 } & N, N^{1} \text {-Bis(2,3-butadienyl)-1,4-butanediamine } \\ \text { NAC } & N \text {-acetylcysteine } \\ \text { ODC } & \text { Ornithine decarboxylase } \\ \text { SSAO } & \text { Semicarbazide-sensitive amine oxidase } \\ \text { SSAT } & \text { Spermidine/spermine } N^{1} \text {-acetyltransferase } \\ \text { SMO } & \text { Spermine oxidase }\end{array}$




\section{Introduction}

The ubiquitous polycationic polyamines spermidine and spermine are known to be required for embryonic development and for the maintenance of mammalian cell proliferation (Heby 1981; Pegg et al. 1982; Agostinelli et al. 2009). Male Gyro (Gy) mice with profound spermine deficiency due to the extensive disruption of both phosphate regulating endopeptidase and spermine synthase gene (Meyer et al. 1998), exhibit the features of smaller size and lower weight than normal mice, whereas spermine synthase overexpressing mice are slightly larger than normal mice (Wang et al. 2004). Mutations in the spermine synthase gene are reported to cause Snyder-Robinson syndrome, an X linked mental retardation disorder condition accompanied by thin habitus and skeletal defects such as osteoporosis (Cason et al. 2003). The polyamine-acetylating enzyme, spermidine/spermine $N^{1}$-acetyltransferase (SSAT), participates in polyamine homeostasis by regulating polyamine export and catabolism. SSAT transgenic mice characteristically lack hair, and have a lean body mass. In contrast, SSAT knock-out mice tend to accumulate fat in their bodies (Jell et al. 2007), suggesting that altered SSAT expression can affect fat metabolism. Furthermore, both spermine and spermidine at physiological concentrations, have been shown to inhibit lipolysis by suppressing cyclic AMP levels and to facilitate glucose transport, which is accompanied by up-regulated conversion of glucose into triacylglycerols in adipocytes of Zucker obese rats (Lockwood et al. 1974; Jamdar et al. 1996).

It has also been suggested that in some cases the polyamines may play an essential role in cellular differentiation (Pegg and McCann 1982; Erwin et al. 1983). The process of adipogenesis or the formation of adipose tissue has become better understood by the study of several cell types such as 3T3-L1 that can be induced to undergo differentiation into adipocytes. Alpha-difluoromethylornithine (DFMO), which is an irreversible inhibitor of ornithine decarboxylase (ODC) (Metcalf et al. 1977), the enzyme producing putrescine and a limiting step in polyamine biosynthesis, prevented the differentiation of 3T3-L1 fibroblasts into adipocytes (Bethell et al. 1981). In 3T3-L1 cells stimulation with insulin (INS) and isobutylmethylxanthine (IBMX) increased twofold putrescine, threefold spermidine within $48 \mathrm{~h}$, and spermine slightly (Erwin et al. 1984). The cells stimulated with INS and IBMX had significantly higher activity of ODC than not stimulated, but the activities of both spermidine synthase and spermine synthase were not altered. Therefore, it appears that the elevations of polyamine contents in the differentiating cells might be not only due to changes in the biosynthetic enzymes but also due to the degradation and/or excretion of these polyamines affected by the stimulation medium
(Erwin et al. 1984). Spermidine is required in 3T3-L1 differentiation, shown by using methylspermidine as spermidine analogues (Vuohelainen et al. 2010). However, the specific roles of individual polyamines during adipogenesis have remained unclear.

trans-4-Methylcyclohexylamine (MCHA) and $\mathrm{N}$-(3aminopropyl)-cyclohexylamine (APCHA) selectively and potently inhibited the activities of spermidine synthase and spermine synthase, respectively. Previous studies showed that each inhibitor markedly decreases cellular spermidine and spermine, respectively, both in rat tissues when they were orally administered to rats and after treatment of HTC cells (Shirahata et al. 1993; Beppu et al. 1995).

In this study, to explore the possible function of spermidine and spermine in adipogenesis, we describe the effect of MCHA and APCHA on lipid accumulation and their opposite effects on 3T3-L1 lipid accumulation during differentiation and maturation. Moreover, we also demonstrate that polyamine catabolism may be involved in lipid metabolism.

\section{Materials and methods}

\section{Materials}

Dulbecco's Modified Eagle's Medium (DMEM), calf serum (CS), penicillin and streptomycin were purchased from Invitrogene (NY, USA). Fetal bovine serum (FBS) was purchased from Nichirei Biosciences Inc. (Tokyo, Japan). Dexamethasone (DEX), IBMX, INS and all other reagents were purchased from Wako Pure Chemical Industries (Osaka, Japan). MCHA, APCHA, $N, N^{1}$-bis(2, 3-butadienyl)-1,4-butanediamine (MDL72527) and $N^{1}$ dansylnorspermine were prepared in this laboratory (Shirahata et al. 1988, 1991; Bey et al. 1985; Takao et al. 2008). $N$-acetylcysteine (NAC) was purchased from Sigma (MO, USA).

\section{Cell culture and differentiation}

Mouse fibroblast line 3T3-Ll preadipocytes were maintained in DMEM, $50 \mathrm{U} / \mathrm{ml}$ penicillin and $50 \mu \mathrm{g} / \mathrm{ml}$ streptomycin, $3.7 \mathrm{mg} / \mathrm{ml} \mathrm{NaHCO}_{3}$, and $10 \% \mathrm{CS}$, with a replacement of media every other day. To induce differentiation, 3T3-L1 preadipocytes were cultured in differentiation medium containing DMEM and 10\% FBS. After confluence, cells were induced to differentiate (designated day 0 ) by addition of $1 \mu \mathrm{M}$ DEX, $0.5 \mathrm{mM}$ IBMX for the first $48 \mathrm{~h}$. From day 2 to day 4, the medium was supplemented with $10 \mu \mathrm{g} / \mathrm{ml}$ INS after which the cells were fed every other day with DMEM containing 10\% FBS from day 4 to day 11. In order to examine the effect of 
polyamines on adipocyte differentiation process, the cells were pretreated 3 days prior to treatment with differentiation medium with the spermidine synthase inhibitor MCHA and spermine synthase inhibitor APCHA. This pretreatment was needed in order to change the cellular polyamine contents efficiently. In order to investigate the effect of polyamines on lipid accumulation in mature 3T3-L1 cells, the cells were treated with MCHA and APCHA from day 6. The inhibitor concentration was set up to $100 \mu \mathrm{M}$, which did not have any influence on cell growth.

\section{Oil Red O staining}

The cells were fixed in $10 \%$ formaldehyde in PBS at room temperature for $30 \mathrm{~min}$, and washed with PBS and stained with filtered Oil Red O solution at room temperature for $5 \mathrm{~min}$. Oil Red O solution was prepared to be dissolved at concentration of $60 \%$ in isopropyl alcohol and to be diluted with an equal volume of water freshly at every experiment. After washing with PBS, the stained triglyceride droplets were photographed.

Measurement of triglyceride contents and glycerol-3phosphate dehydrogenase activity

Cells at the designated stage of induction of differentiation were washed twice with PBS and lysed by brief sonication. The triglyceride levels in the lysates were quantified using the Triglyceride E Test WAKO kit (Wako Pure Chemicals, Osaka, Japan) according to the manufacturer's protocol. Glycerol-3-phosphate dehydrogenase (GPDH) activity was assayed by recording the initial rate of oxidation of NADH at $340 \mathrm{~nm}$ at $30^{\circ} \mathrm{C}$ (Wise et al. 1979). The cells were washed twice with PBS, and removed by scraping into enzyme extraction buffer $(50 \mathrm{mM}$ Tris- $\mathrm{HCl}$ buffer $\mathrm{pH} 7.5$ at $30^{\circ} \mathrm{C}, 1 \mathrm{mM}$ EDTA and $1 \mathrm{mM} \beta$-mercaptoethanol). After centrifugation at $9,200 \times g$ for $5 \mathrm{~min}$ at $4^{\circ} \mathrm{C}$, GPDH specific activity in the supernatant was measured using a GPDH Assay Kit (Takara Bio. Inc., Shiga, Japan) as an estimation for adipogenesis.

\section{Determination for SSAT activity}

SSAT enzyme activity was assayed as described previously (Takao et al. 2008). Cells were washed twice with PBS and removed by scraping into SSAT extraction buffer $(1 \mathrm{mM}$ EDTA, $10 \mathrm{mM}$ Tris- $\mathrm{HCl} \mathrm{pH} 7.0$ at $4^{\circ} \mathrm{C}$ and $2.5 \mathrm{mM}$ DTT) and lysed by brief sonication. The homogenate was centrifuged $15,600 \times \mathrm{g}$ for $20 \mathrm{~min}$ at $4^{\circ} \mathrm{C}$. Aliquots of the supernatant containing the same amounts $(50 \mu \mathrm{g})$ of protein were mixed with $0.1 \mathrm{M}$ Tris- $\mathrm{HCl} \mathrm{PH} 7.8,50 \mu \mathrm{M}$ acetyl-CoA and $40 \mu \mathrm{M} N^{1}$-dansylnorspermine for the assay. After incubation at $37^{\circ} \mathrm{C}$ for $10 \mathrm{~min}$, TCA was added immediately to stop the reaction, and the mixture centrifuged $15,600 \times g$ for $20 \mathrm{~min}$ at $4^{\circ} \mathrm{C}$. An aliquot of the supernatants was injected onto fluorescence-detective HPLC (Takao et al. 2008).

Polyamine analysis

Cells were washed twice with PBS and polyamines were extracted in $10 \%$ trichloroacetic acid. The extracts were directly injected onto the OPA-postcolumn ion-exchange HPLC system (Shirahata et al. 1993).

Statistical analysis

Results were expressed as mean $\pm \mathrm{SE}$, and compared using Student's $t$ test. $p<0.05$ was considered statistically significant.

\section{Results and discussion}

Changes in polyamine contents and SSAT activity during 3T3-L1 adipose conversion

3T3-L1 cells were stimulated to differentiate into adipocytes by the addition of IBMX, DEX, and INS. This
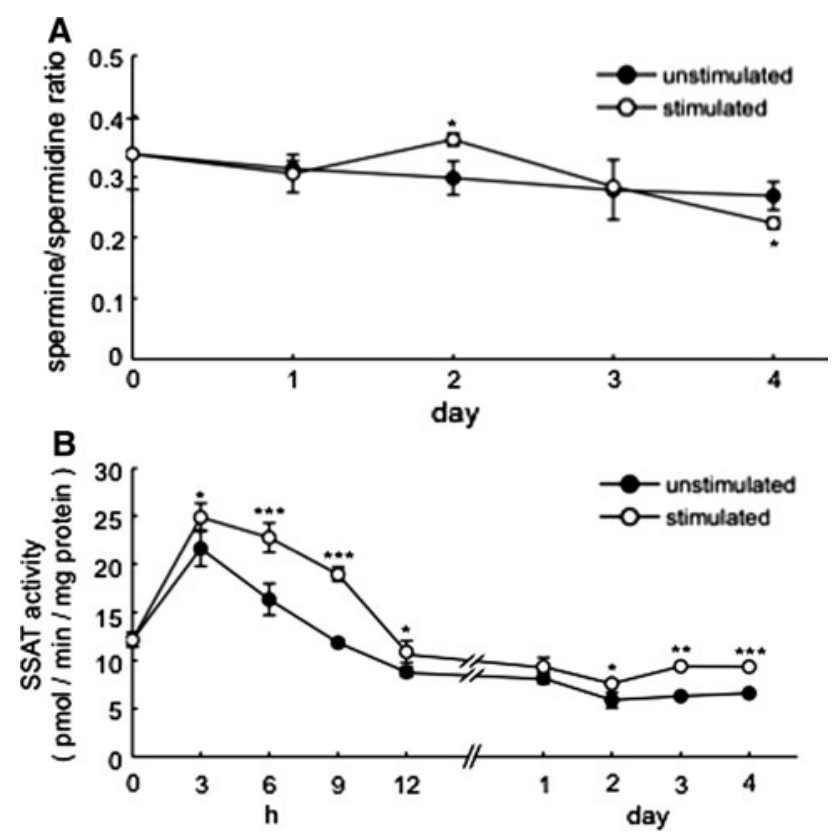

Fig. 1 Changes in spermine/spermidine ratios and SSAT activity of 3T3-L1 during differentiation with IBMX, DEX and INS. Spermine/ spermidine ratios (a) and SSAT activity (b) in 3T3-L1 cells at indicated times from day 0 to day 4 were measured. Results shown for control cells stimulated with IBMX, DEX and INS (open circles) and blank cells without the stimulus (filled circles) at times shown after start of stimulation. Results represent the mean \pm SE. $* * * p<0.001$, $* * p<0.01, * p<0.05$ compared with control 

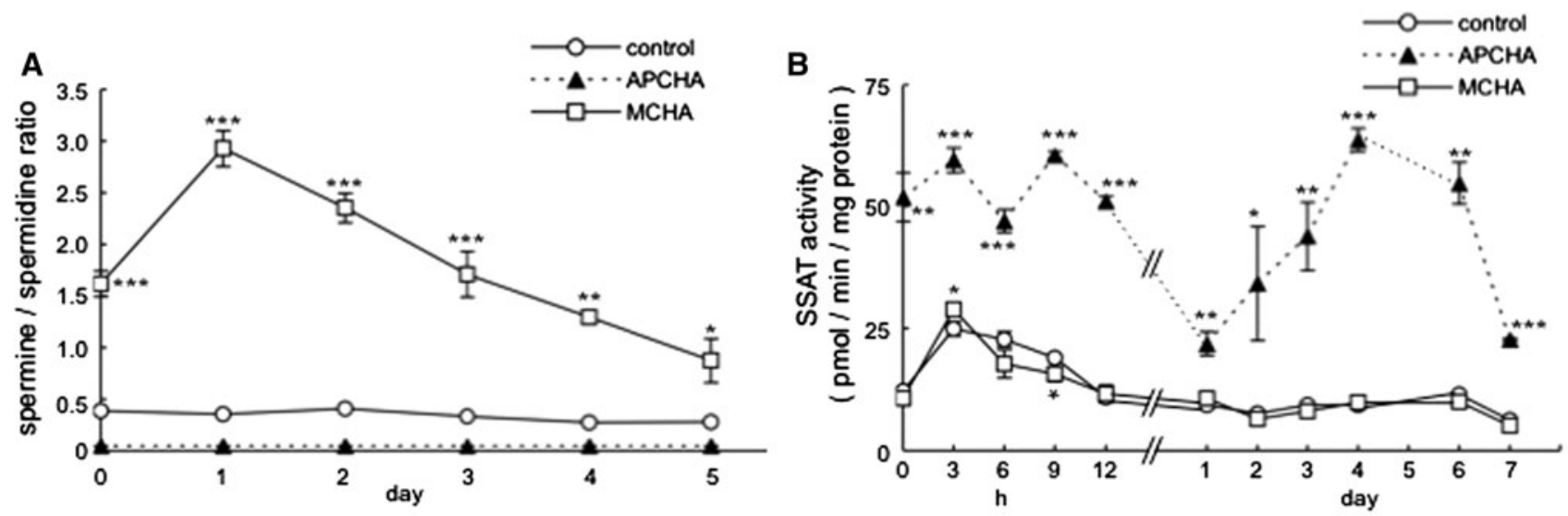

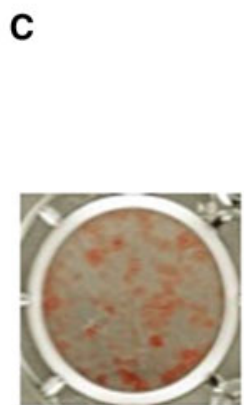

control

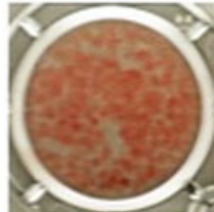

APCHA

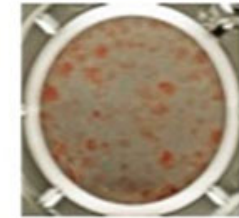

$\mathrm{MCHA}$
D

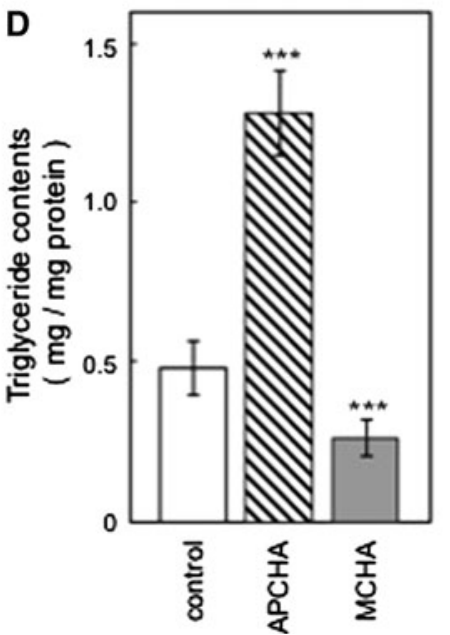

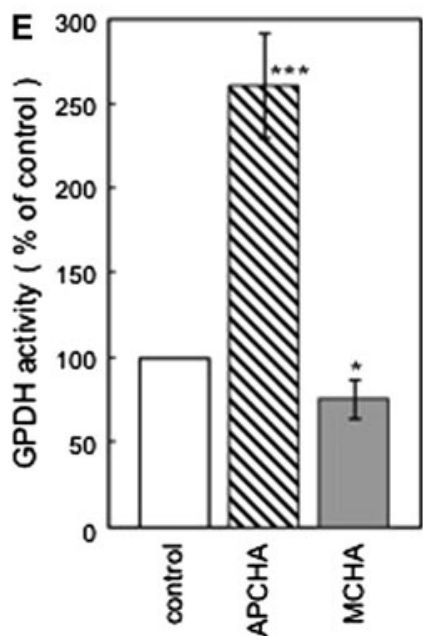

Fig. 2 The effect of APCHA or MCHA on adipocyte differentiation. Spermine/spermidine ratios (a) and SSAT activity (b) in 3T3-L1 cells treated with MCHA or APCHA for day-3 to day-11 according to "Materials and methods", were measured during differentiation. Results shown for control cells (open circles with solid line), MCHAtreated cells (open squares with solid line) and APCHA-treated cells

mixture, which is frequently used to induce differentiation, had never been tested for study on polyamine to our knowledge. The adipocyte differentiation status was estimated by staining with Oil Red $\mathrm{O}$ and quantification for triglyceride. The spermine/spermidine ratios were found to increase slightly at day 2 , and then decreased at day 4 after the treatment with the mixture of the inducers (Fig. 1a). To test whether the polyamine metabolism could be involved in the changes in cellular polyamine ratios after stimulation, spermidine/spermine- $N^{1}$-acetyltransferase (SSAT) activity, which is one of major polyamine metabolic enzymes, inducible in many normal and disease processes (Min et al. 2002), was measured during 3T3-L1 adipogenesis. The activity of SSAT in stimulated cells taken as a control was found to be significantly higher than that in unstimulated cells taken as a blank. The SSAT activity of the control transiently peaked at $3 \mathrm{~h}$ and was 1.9 -fold that of the blank cells at $9 \mathrm{~h}$ after stimulus for differentiation

(filled triangles with dotted line). c Cells were stained with Oil Red O at day 10 after the stimulus. d Triglyceride contents were measured at day 11. e GPDH activity was measured at day 7. Results represent the mean \pm SE. $* * * p<0.001, * * p<0.01, * p<0.05$ compared with control

(Fig. 1b). The results indicate that both spermine/spermidine ratios and activity of its metabolic enzymes could be involved in adipogenesis.

Effects of MCHA or APCHA on polyamine contents, SSAT activity and differentiation of 3T3-L1 cells

There is no report at present on studies of the effect of cellular spermine/spermidine ratios on differentiation of 3T3-L1 cells using spermidine synthase inhibitor MCHA and spermine synthase inhibitor APCHA. Addition of $100 \mu \mathrm{M}$ MCHA or APCHA, which had no effect on cell growth (data not shown), was used to study the functions of polyamines by treatment starting from 3 days prior to induction for differentiation. MCHA maintained a high spermine/spermidine ratio during differentiation in 3T3-L1 cells (Fig. 2a). Little difference was seen in the SSAT activity between in MCHA-treated cells and control 

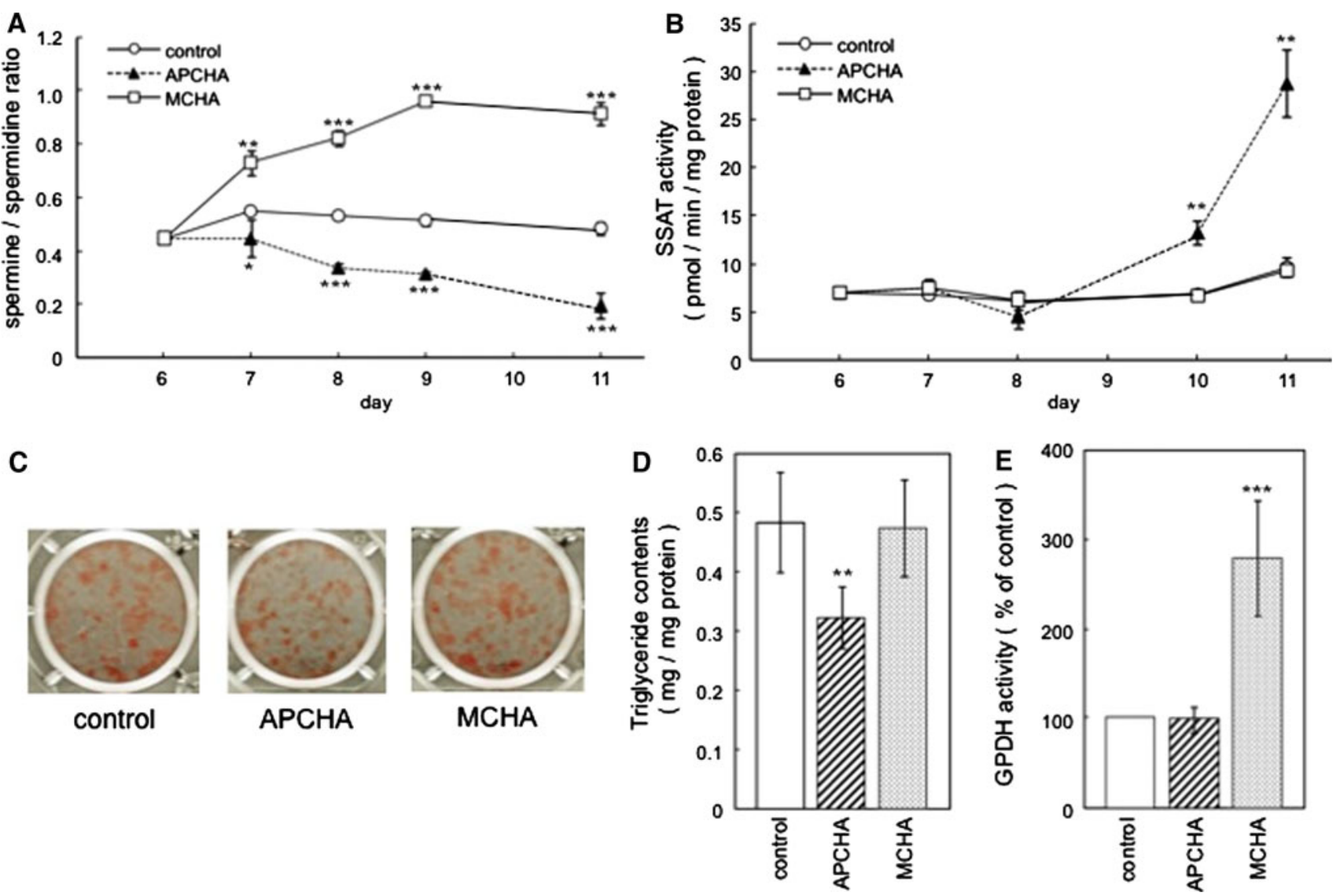

Fig. 3 The effect of MCHA or APCHA on lipid accumulation in mature adipocytes. The differentiated cells were treated with MCHA or APCHA from day 6. Results shown for control cells (open circles with solid line), MCHA-treated cells (open squares with solid line) and APCHA-treated cells (filled triangles with dotted line). Spermine/ spermidine ratios (a) and SSAT activity (b) were measured at

(Fig. 2b). In contrast to MCHA, APCHA decreased spermine/spermidine ratios in 3T3-L1 cells significantly (Fig. 2a). SSAT activity in APCHA-treated cells was significantly enhanced during the adipocyte differentiation by 2.4-, 3.2- and 6.8-fold than that in control at $3 \mathrm{~h}, 9 \mathrm{~h}$ and day 4 , respectively (Fig. $2 b$ ).

The effect of the inhibitors on adipocyte differentiation was investigated by Oil Red O staining for lipid drops and by the measurement of intracellular triglyceride contents. MCHA was found to decrease Oil Red O staining (Fig. 2c). Both triglyceride contents and GPDH activity in MCHAtreated cells were lower ( 0.5 -fold and 0.7 -fold, respectively) than those in control, respectively (Fig. 2d, e). On the other hand, APCHA significantly increased Oil Red O staining (Fig. 2c), and also increased both triglyceride contents and GPDH activity by 2.7 -fold and by 1.7 -fold, respectively (Fig. 2d, e). In mouse preadipocyte Ob1771 cells, the decrease in cellular spermine/spermidine ratios by treatment with putrescine or spermidine and exposure to growth hormone enhanced GPDH activity (Amri et al.

indicated times from day 6 to day 11. c The effect of inhibitors on lipid accumulation. Cells were fixed and stained with Oil Red O at day 10. d Triglyceride contents at day 11 and e the activity of GPDH at day 14 were measured. Results represent the mean $\pm \mathrm{SE}$. $* * * p<0.001, * * p<0.01, * p<0.05$ compared with control

1986a, b). The elevated GPDH activity could therefore be explainable by decrease in cellular spermine/spermidine ratios by APCHA. The decline in GPDH activity by MCHA-treatment is consistent with an increase in the ratios.

In our previous study, to research the effect of MCHA and APCHA on enzyme activity on rat hepatoma cells (HTC cells), no significant changes in the SSAT activities occurred during the treatment (Beppu et al. 1995). The results shown in this paper illustrate that the alternation of spermine/spermidine ratios and the SSAT enzyme activity could be involved in adipocyte differentiation.

Effects of MCHA or APCHA on lipid accumulation in mature adipocytes

In order to examine the effect of the inhibitors on lipid accumulation in the mature stage, the differentiated cells were treated with $100 \mu \mathrm{M}$ MCHA or APCHA from day 6 . Spermine/spermidine ratios were gradually increased by 

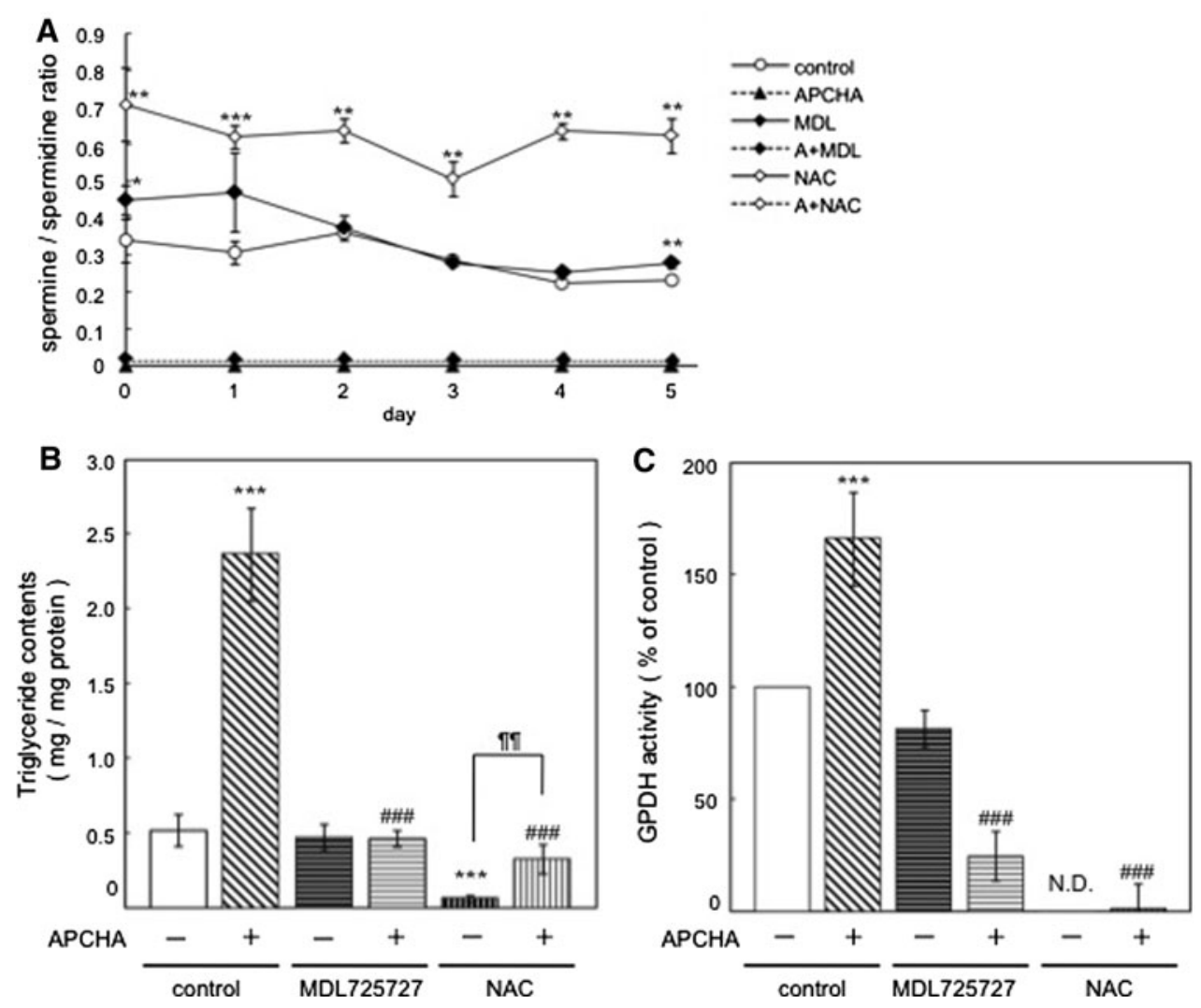

Fig. 4 The effect of MDL72527 and NAC on APCHA-enhanced differentiation of 3T3-L1 cells. Cells were treated with MDL72527 $(5 \mu \mathrm{M})$ in the presence or absence of APCHA. Cells were pretreated with NAC $(5 \mathrm{mM}) 1$ day prior to induction for differentiation. a spermine/spermidine ratios, b triglyceride contents at day 11 and c GPDH activity at day 8 were analyzed after stimulus for differentiation. Results shown for control cells (open circles with solid line), treated with APCHA (filled triangles with dotted line) and

MCHA, and decreased by APCHA at $24 \mathrm{~h}$ after treatment (Fig. 3a) because polyamine synthesis was affected by treatment of MCHA or APCHA even in mature cells with depression of cellular proliferation. APCHA elevated SSAT activity significantly up to 3.0-fold higher than control at day 11. In contrast to APCHA's effect, SSAT activities in MCHA-treated cells were similar to those in control (Fig. 3b).

MCHA slightly increased Oil Red O staining, and had no effect on triglyceride contents (Fig. 3c, d). The GPDH activity was increased up to 2.8-fold by MCHA in comparison with control (Fig. 3e). APCHA was found to decrease both Oil Red O staining and triglyceride contents by 33\% in mature adipocytes (Fig. 3c, d), although APCHA did not change GPDH activity (Fig. 3e).

MCHA increased and APCHA decreased lipid accumulation in mature adipocytes whereas MCHA decreased and APCHA increased lipid accumulation in preadipocytes, which interestingly appeared to demonstrate an opposite effect of the two polyamine synthesis inhibitors

MDL72527 (filled diamonds with solid line), MDL72527 with APCHA (filled diamonds with dotted line), NAC (open diamonds with solid line) and NAC with APCHA (open diamonds with dotted line). Results represent the mean $\pm \mathrm{SE}$. $* * * p<0.001, * * p<0.01$,

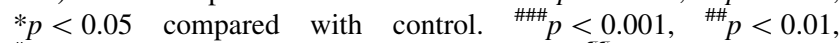
${ }^{\#} p<0.05$ compared with APCHA-treated cells. ${ }^{~}{ }_{p} p<0.01$ compared with NAC-treated cells. $N D$ not detectable

on adipogenesis in differentiating and mature adipocytes. The above results suggest that not only spermine/spermidine ratios but also polyamine-metabolizing enzymes leading to changes in spermine/spermidine ratios could be involved in adipogenesis at each stage, and might indicate an additional role of polyamine in a cellular model of adipogenesis.

MDL72527 and NAC inhibit the effect of APCHA-induced lipid accumulation

Mammalian polyamine catabolism is a recycling pathway that converts spermine to spermidine and spermidine to putrescine with the production of $\mathrm{H}_{2} \mathrm{O}_{2}$ and acetamidopropanal or aminopropanal, via the concerted action of SSAT and acetylpolyamine oxidase (AcPAO) or via spermine oxidase (SMO) without the need of the acetylation step, respectively. Considering the above results on the changes in SSAT activity during adipogenesis, especially in the presence of APCHA, we examined the influence of 
the polyamine catabolic enzyme inhibitor MDL72527, which inhibits both AcPAO and SMO activity, to study adipogenesis promotion by APCHA.

MDL72527 did not affect cell growth (data not shown) or spermine/spermidine ratios by itself (Fig. 4a). MDL72527 prevented an APCHA-promoted effect on cellular triglyceride content (Fig. 4b), and GPDH activity (Fig. 4c). NAC, a scavenger for reactive oxygen species and a precursor for GSH reducing the adipogenic action by the amines (Faruqi et al. 1997), was found to increase spermine/spermidine ratios by 2.3 -fold during adipogenesis (Fig. 4a). NAC completely inhibited triglyceride production (Fig. 4b) and APCHA-upregulated GPDH activity (Fig. 4c). Several oxidative products such as an aldehyde and $\mathrm{H}_{2} \mathrm{O}_{2}$ are known to involved in adipocytes differentiation in the insulin signaling system (Mahadev et al. 2001; Lin et al. 2006; Kim et al. 2006). The results suggest that the oxidative stress, produced from enhanced polyamine catabolism by APCHA in addition to the change in spermine/spermidine ratios, could have a function similar to the insulin signal (Fontana et al. 2001). NAC itself fully suppressed adipocyte differentiation in control cells, but not completely in APCHA-treated cells probably due to the insufficient inhibition of oxidants produced by APCHAtreatment.

Amines such as tyramine or benzylamine can mimic or reinforce several of the insulin effects on adipocyte differentiation in 3T3-F442A and 3T3-L1 cells mainly by generating $\mathrm{H}_{2} \mathrm{O}_{2}$ produced by amine oxidases like semicarbazide-sensitive amine oxidase (SSAO) or monoamine oxidase (MAO) (Fontana et al. 2001; Mercier et al. 2001; Carpéné et al. 2006). This fact was suggested by the suppression in differentiation obtained by using their inhibitors and antioxidants. Our results do not exclude the possibility that the aldehydes and $\mathrm{H}_{2} \mathrm{O}_{2}$ generated via polyamine oxidation by AcPAO or SMO could play a part of roles in adipogenesis.

In this study, we have shown that both spermine/spermidine ratios and activity of its metabolic enzymes could be involved in adipogenesis although there are issues to be resolved in process of adipogenesis. We found that MCHA and APCHA have their own specific effects on both preadipocytes and mature adipocytes with the changes in SSAT activity, shown prominently in the APCHA-treated cells. These findings also suggest that the control of polyamine metabolic enzyme activity could regulate adipogenesis and that the inhibitors are valuable tools for research on lipid metabolism.

Open Access This article is distributed under the terms of the Creative Commons Attribution Noncommercial License which permits any noncommercial use, distribution, and reproduction in any medium, provided the original author(s) and source are credited.

\section{References}

Agostinelli E, Marques MPM, Calheiros R et al (2009) Polyamines: fundamental characters in chemistry and biology. Amino Acids 38:393-403

Amri EZ, Barbaras R, Doglio A, Dani C, Grimaldi P, Ailhaud G (1986a) Role of spermidine in the expression of late markers of adipose conversion. Effects of growth hormone. Biochem $\mathbf{J}$ 239:363-370

Amri EZ, Dani C, Doglio A, Etienne J, Grimaldi P, Ailhaud G (1986b) Adipose cell differentiation: evidence for a two-step process in the polyamine-dependent Ob1754 clonal line. Biochem J 238:115-122

Beppu T, Shirahata A, Takahashi N, Hosoda H, Samejima K (1995) Specific depletion of spermidine and spermine in HTC cells treated with inhibitors of aminopropyltransferases. J Biochem 117:339-345

Bethell DR, Pegg AE (1981) Polyamines are needed for the differentiation of 3T3-L1 fibroblasts into adipose cells. Biochem Biophys Res Commun 102:272-278

Bey P, Bolkenius FN, Seiler N, Casara P (1985) N-2, 3-Butadienyl-1, 4-butanediamine derivatives: potent irreversible inactivators of mammalian polyamine oxidase. J Med Chem 28:1-2

Carpéné C, Daviaud D, Boucher J et al (2006) Short- and Long-term insuline-like effects of monoamine oxidases and semicarbazidesensitive amine oxidase substrates in cultured adipocytes. Metabolism 55:1397-1405

Cason AL, Ikeguchi Y, Skinner C et al (2003) X-linked spermine synthase gene (SMS) defect: the first polyamine deficiency syndrome. Eur J Hum Genet 11:937-944

Erwin BG, Ewton DZ, Florini JR, Pegg AE (1983) Polyamine depletion inhibits the differentiation of L6 myoblast cells. Biochem Biophys Res Commun 114:944-949

Erwin BG, Bethell DR, Pegg AE (1984) Role of polyamines in differentiation of 3T3-L1 fibroblasts into adipocytes. Am J Physiol Cell Physiol 246:C293-C300

Faruqi RM, Poptic EJ, Faruqi TR, De la Motte C, DiCorleto PE (1997) Distinct mechanisms for N-acetylcysteine inhibition of cytokine-induced E-selectin and VCAM-1 expression. Am J Physiol 273:H817-H826

Fontana E, Boucher J, Marti L, Lizcano JM, Testar X, Zorzano A, Carpéné C (2001) Amine oxidase substrates mimic several of the insulin effects on adipocytes differentiation in 3T3 F442A cells. Biochem J 356:769-777

Heby O (1981) Role of polyamines in the control of cell proliferation and differentiation. Differentiation 19:1-20

Jamdar SC, Cao WF, Samaniego E (1996) Relationship between adipose polyamine concentrations and triacylglycerol synthetic enzymes in lean and obese Zucker rats. Enzyme Protein 49:222-230

Jell J, Merali S, Hensen ML et al (2007) Genetically altered expression of spermidine/spermine $N^{1}$-acetyltransferase affects fat metabolism in mice via acetyl-CoA. J Biol Chem 282:8404-8413

Kim JR, Ryu HH, Chung HJ, Lee JH, Kim SW, Kwun WH, Baek SH, Kim JH (2006) Association of anti-obesity activity of $\mathrm{N}$ acetylcysteine with metallothionein-II down-regulation. Exp Mol Med 38:162-172

Lin Y, Berg AH, Iyengar P et al (2006) The hyperglycemia-induced inflammatory response in adipocytes the role of reactive oxigene species. J Biol Chem 280:4617-4626

Lockwood DH, East LE (1974) Studies of the insulin-like actions of polyamines on lipid and glucose metabolism in adipose tissue cells. J Biol Chem 249:7717-7722

Mahadev K, Wu X, Zilbering A, Zhu L, Lawrence JT, Goldstein BJ (2001) Hydrogen peroxide generated during cellular insulin 
stimulation is integral to activation of the distal insulin signaling cascade in 3T3-L1 adipocytes. J Biol Chem 276:48662-48669

Mercier N, Moldes M, Hadri KE, Fève B (2001) Semicarbazidesensitive amine oxidase activation promotes adipose conversion of 3T3-L1 cells. Biochem J 358:335-342

Metcalf BW, Bey P, Danzin C, Jung MJ, Casara P, Vevert JP (1977) Catalytic irreversible inhibition of mammalian ornithine decarboxylase (E.C.4.1.1.17) by substrate and product analogs. J Am Chem Soc 100:2551-2553

Meyer RA, Henley CM, Meyer MH, Morgan PL, McDonald AG, Mills C, Price DK (1998) Partial deletion of both the spermine synthase gene and the Pex gene in the X-linked hypophosphatemic, gyro (Gy) mouse. Genomics 48:289-295

Min SH, Simmen RC, Alhonen L, Halmekytö M, Porter CW, Jänne J, Simmen FA (2002) Altered levels of growth-related and novel gene transcripts in reproductive and other tissues of female mice overexpressing spermidine/spermine $\quad N^{1}$-acetyltransferase (SSAT). J Biol Chem 277:3647-3657

Pegg AE, McCann PP (1982) Polyamine metabolism and function. Am J Physol 243:C212-C221

Shirahata A, Morohoshi T, Samejima K (1988) Trans-4-methylcyclohexylamine, a potent new inhibitor of spermidine synthase. Chem Pharm Bull 36:3220-3222
Shirahata A, Morohoshi T, Fukai M, Akatsu S, Samejima K (1991) Putrescine or spermidine binding site of aminopropyltransferases and competitive inhibitors. Biochem Pharmacol 41:205-212

Shirahata A, Takahashi N, Beppu T, Hosoda H, Samejima K (1993) Effects of inhibitors of spermidine synthase and spermine synthase on polyamine synthesis in rat tissues. Biochem Pharmacol 45:1897-1903

Takao K, Miyatake S, Fukazawa K, Wada M, Sugita Y, Shirahata A (2008) Measurement of spermidine/spermine $N^{1}$-acetyltransferase activity by high-performance liquid chromatography with $N^{1}$-dansylnorspermine as the substrate. Anal Biochem 376: 277-279

Vuohelainen S, Pirinen E, Cerrada-Gimenez M et al (2010) Spermidine is indispensable in differentiation of 3T3-L1 fibroblasts to adipocytes. J Cell Mol Med 14:1683-1692

Wang X, Ikeguchi Y, McCloskey DE, Nelson P, Pegg AE (2004) Spermine synthesis is required for normal viability, growth, and fertility in the mouse. J Biol Chem 279:51370-51375

Wise LS, Green H (1979) Participation of one isozyme of cytosolic glycerophosphate dehydrogenase in the adipose conversion of 3 T3 cells. J Biol Chem 254:273-275 